\title{
Biosimilars: Patient Perspectives, Challenges and Emerging Solutions: Current Opinions
}

\section{Frapaise FX*}

President of the French Association of Pharmaceutical Medicine, France

*Corresponding author: Frapaise FX, President of the French Association of Pharmaceutical Medicine, France, E-mail: xavierfrapaise@yahoo.com

Received: 17 May, 2019 | Accepted: 13 Jun, 2019 | Published: 21 Jun, 2019

Citation: Frapaise FX (2019) Biosimilars: Patient Perspectives, Challenges and Emerging Solutions: Current Opinions. J Drug Res Dev 5(1): dx.doi. org/10.16966/2470-1009.148

Copyright: (c) 2019 Frapaise FX. This is an open-access article distributed under the terms of the Creative Commons Attribution License, which permits unrestricted use, distribution, and reproduction in any medium, provided the original author and source are credited.

\section{Abstract}

Current evidence suggests that while most patients have a limited understanding of the risks and benefits of biosimilars, they generally trust their physician to prescribe the right compound. Unfortunately, training and education programs on biosimilars targeting prescribers have had a limited reach. Most physicians believe that so-called reference compounds are cast-in-stone, and are not aware of the evolution of the manufacturing process of many of these reference compounds. Physicians are rarely aware of the product that will be delivered by the hospital pharmacists, and, despite their legal obligations, do not necessarily have the time to discuss the reasons for the prescription of a biosimilar product with their patients.

Yet, analytical methods have enabled a detailed and precise profiling of biosimilars, as well as a better understanding of the relationship between the structure and function of proteins, rendering large phase-3 trials no longer necessary. Indeed, phase-3 trials have failed to show any meaningful, clinical difference between originator and biosimilars, when analytical similarity was established. Regulators have also significantly evolved, and are becoming more comfortable with the concept of extrapolation of indications. Based on the results in one single indication, products given to oncology patients, such as peg-filgrastim, are now approved in the U.S. and E.U., based on a solid CMC package, and phase-1 trials performed with volunteers, without a single cancer patient enrolled in the clinical program.

Hence, significant progress has been recently observed in the field of biosimilars. In order to address the remaining communication challenge, biosimilar companies should with the support of independent scientific and medical societies: (A) significantly invest in the training of medical professionals, including nurses (B) Develop patient information/assistance programs, (C) Partner with patients organizations and regulators, (D) Organize Patient Advisory Boards to ensure the study is feasible and that informed consent forms provide accurate and useful information, and (E) Economically incentivize patients to accept a biosimilars prescription, and (F) Above all, consider patients as partners, and no longer as "subjects". Patients, prescribers, and payers must also accept that biosimilar adoption is the only viable option if public health insurances wish to keep reimbursing therapeutic innovations such as CAR-T and checkpoint inhibitors; all of these actors must realize that biosimilar adoption is, in effect, one of the manifestations of an evolving Social Contract, by which patients accepting the prescription of biosimilars will enable the access to expensive and life-saving biologics to a larger population.

Keywords: Biosimilars; Patient-Centricity

\section{Introduction}

Despite the fact that generics and reference compounds have exactly the same structures and functions, many patients in 2019 are still reluctant to receive generic compounds from their pharmacists. The issue is that patients are uncomfortable receiving products that can be slightly more effective, but also slightly less effective. Thus, it is not surprising that uninformed patients express even deeper reservations about biosimilars, which are, by definition, "similar, but not identical to the reference compounds."

Yet, biosimilars are expected to play a key role in improving patient access to biological therapies and addressing concerns regarding the escalating cost of health care. Indeed, national health insurance systems that provide near-full reimbursement of prescribed drugs are struggling with the concept of reimbursing the high cost of innovative therapies, such as checkpoint inhibitors and CAR-T, without mentioning the recent example of gene therapy. The nature, root causes and emerging solutions to the current patient's attitude towards biosimilars are the subjects of this review.

\section{Facts and Perceptions}

We are getting there, but.

Robust analytical methods are available and the protein structure-function relationship is better understood

Sophisticated and complementary methods (so-called "orthogonal methods"), enable a functional and structural comparability assessment between originators and candidate biosimilars, hence it 
is now possible to compare biosimilars to reference compounds on multiple levels: primary and secondary structure, post-translational modifications, binding to receptors, etc.

Even more important than these comparability exercises is that the relationship between the structure and function of these biotherapeutics is much better understood; the influence of glycosylation patterns on pharmacokinetics and immunogenicity is one example of this phenomenon. Considering the lack of sensitivity of many clinical models to detect meaningful differences between follow-on biologics and reference compounds, it has even been suggested to stop running large and expensive phase- 3 clinical trials when similarity has been analytically conveyed in well-designed phase 1 trials [1].

\section{Industry perspective}

Rough estimates demonstrate that it takes at least $1.5-2$ years to evolve from the phase- 3 trial design to the production of an audited clinical trial report [1]. Most phase- 3 trials include around 600 patients with a cost of $€ 30-50$ million. Sourcing the reference compound can be extremely challenging and often very costly. Recent developments have demonstrated that these trials can hardly be justified from a scientific perspective, hence are not ethically justifiable.

The perspective of manufacturers of reference compounds is evidently starkly different, as they aim to protect their investment for as long as possible; manufacturers, particularly in the United States, have been quite successful in limiting the access of biosimilars to the U.S. market through patent litigation and, at times, by delivering negative messages on biosimilars.

\section{The "Reference compound myth", A.K.A the "Best kept secret"...}

Most clinicians still believe that the structure of the reference compounds is "cast instone", never changes and is, therefore, reliable, while the other biosimilars side it is only similar, and not identical to this "cast-in-stone" reference compound. Schneider CK [2] have clearly demonstrated that this interpretation is far from the reality with products such as Remicade ${ }^{\circ}$ or Humira ${ }^{\circ}$, which have modified their manufacturing process more than 15 , if not 30 , times (see images $\mathrm{A}$ and B below). Clinicians who have prescribed Remicade ${ }^{\oplus}$ or Humira ${ }^{\circ}$ for many years already have volens/nolens a significant experience of biosimilarity (Figure 1).

Similarly, as reported by Mehr SR, et al. [3], reference drugs may have gone through a series of changes in the years since their approval, including those caused by alterations in the manufacturing process, which raises the following question: is a biologic produced 15 years ago a Biosimilar of itself, today. One example of differences between lots of reference product was illustrated by the fact that Sandoz was required to prove that the more recently manufactured Enbrel was clinically equivalent to older versions of Enbrel, even though there were differences observed in a potency assay [4].

These publications show the important role independent scientific and medical societies should play in providing prescribers and patients with objective information on biosimilars.

\section{Regulators evolving perspective}

Regulators are familiarizing themselves with biosimilars, and are no longer requesting animal studies as a part of biosimilar applications. Currently, regulators still tend to differentiate "relatively small" proteins, such as peg-filgrastim, and much larger proteins, such as monoclonal antibodies (e.g. adalimumab and rituximab); for the former, approval can be obtained based on a solid CMC and phase-1 package, while for the latter, large phase- 3 trials are still requested, even if the relevance of such a demand is increasingly challenged [1]. The FDA's favorable inclination vis-à-vis biosimilars is further illustrated by how the agency now dedicates fees to expediting the review process for biosimilar biological products.

The lack of regulatory harmony (concerning the naming of marketed intended copies) as well as interchangeability is among the remaining challenges that regulators collaborating with the biosimilar industry will have to address.

\section{Clinical evidence}

No recent clinical trial or switch trial comparing an analytically similar biosimilar compound to a reference compound has shown a meaningful clinical difference between the compared treatments.

Olteanu R, et al. [5] recently published a systematic review of the literature that was carried out in order to collect all published randomized control trials that investigate biosimilars with their reference medicine (Infliximab, Adalimumab, Etanercept, Ustekinumab) in chronic inflammatory diseases (psoriasis, psoriatic arthritis, rheumatoid arthritis, ankylosing spondylitis, crohn's disease, ulcerative colitis) by using the Medline (PubMed) databases. The authors concluded that all of the biosimilars tested have shown close comparability to their reference medicinal products in terms of physical, biological and clinical characteristics.

To evaluate the possibility of switching from reference biological medicines to biosimilars could lead to altered clinical outcomes, including enhanced immunogenicity, compromised safety, and diminished efficacy for patients. A systematic literature review was conducted of all switching studies between related biologics (including biosimilars. The authors analyzed available data from 90 studies that had enrolled 14,225 unique individuals, and included, in their review, the bio-proteins used in supportive care as well as those used as therapeutic agents. The medicines contained seven different molecular entities that were approved to treat 14 different diseases. The great majority of the publications did not report differences in immunogenicity, safety, or efficacy. The nature and intensity of safety signals reported after switching from reference medicines to biosimilars were the same as those already known from continued use of the reference medicines alone. Three, large, multiple switch studies with different biosimilars did not show differences in efficacy or safety after multiple switches between reference medicine and biosimilar, though two other publications reported a loss of efficacy or increased dropout rates.

Cohen HP, et al. [6] concluded that these analyzed results provide reassurance to healthcare professionals, as well as to the public, that the risk of immunogenicity-related, safety concerns and diminished efficacy is unchanged after switching from a reference biologic to a biosimilar medicine.

However, due to a lack of adequate information communicated to patients, there may exist a nocebo effect, as reported by Pouillon L, et al. [7] and Boone NW, et al. [8]. These authors enrolled a group of 125 patients (of which 73 crohn's with disease, 28 with ulcerative colitis, nine with rheumatoid arthritis, ten with psoriatic arthritis, and five with ankylosing spondylitis). Though no statistically significant changes in efficacy and safety were observed in any of the indications after a median of four infusions in 9 months of study, "a withdrawal rate of $12.8 \%$ was observed and attributed to a nocebo response among the patients during a minimal observation period of 6 months after the transition to biosimilar infliximab". The overall nocebo response rate 


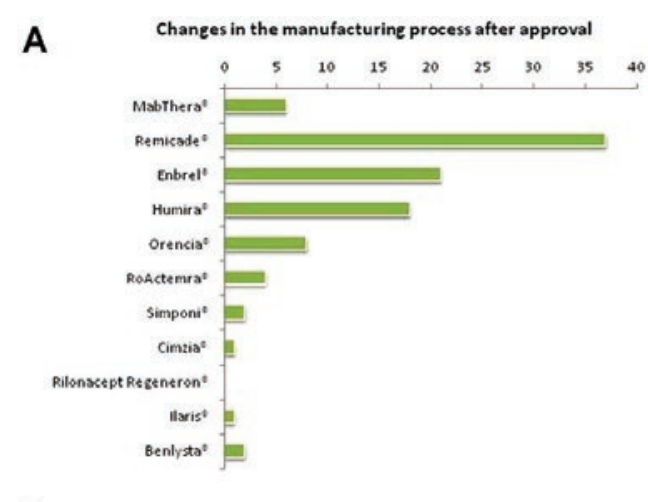

B

\begin{tabular}{|c|c|c|}
\hline mAb/ceptproduct & $\begin{array}{c}\text { non-proprietary } \\
\text { name }\end{array}$ & $\begin{array}{l}\text { Date of licensing in } \\
\text { the EU }\end{array}$ \\
\hline Remicade ${ }^{\circ}$ & inflikimab & 13-08-1999 \\
\hline Enbrel* & etanercept & $03-02-2000$ \\
\hline Humira* & adalimumab & 08-09-2003 \\
\hline MabThera (RA indication) & rituximab & $06-07-2006$ \\
\hline Orencia" & abatacept & 21-05-2007 \\
\hline RoActemra ${ }^{*}$ & tocillizimab & $16-01-2009$ \\
\hline Simponi" & golimumab & 01-10-2009 \\
\hline Cimziat & certolizumab pegol & $01-10-2009$ \\
\hline Rilonacept Regeneron ${ }^{*}$ & rillonacept & 23-10-2009 \\
\hline Haris* & canakinumab & 23-10-2009 \\
\hline Benlysta" & belimumab & 13-07-2011 \\
\hline Biosimilar & $\begin{array}{c}\text { non- } \\
\text { proprietary } \\
\text { name }\end{array}$ & $\begin{array}{c}\text { Date of } \\
y \text { licensing in the } \\
\text { EU }\end{array}$ \\
\hline Omnitrope ${ }^{*}$ & somatropin & 12-04-2006 \\
\hline Valtropin ${ }^{*}$ & somatropin & $24-04-2006$ \\
\hline $\begin{array}{l}\text { Binocrit } \% / \text { Abseamed }{ }^{\oplus /} \\
\text { Epoetin alfahexal }{ }^{*}\end{array}$ & epoetin alfa & 28-08-2007 \\
\hline Silapo*/Retactrit & epoetinzeta & $18-12-2007$ \\
\hline $\begin{array}{l}\text { Ratiograstim/Biograstim } \% / \\
\text { Tevagrastim }\end{array}$ & filgrastim & 15-09-2008 \\
\hline Zarzio"/Filgrastim Hexal" & filgrastim & 06-02-2009 \\
\hline Nivestim ${ }^{*}$ & filgrastim & 08-06-2010 \\
\hline
\end{tabular}
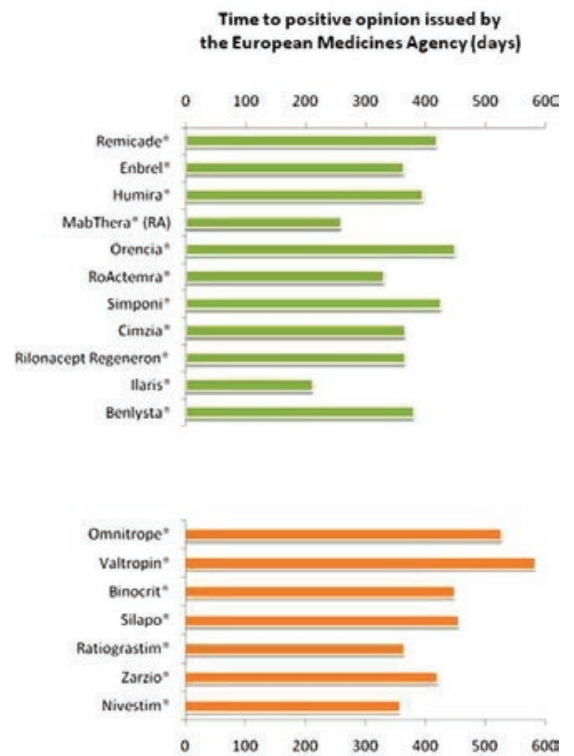

Figure 1: Changes in manufacturing process of Reference Compounds (Schneider).

did not differ between the studied indications. This likely means that enforcing mandatory, non-medical switching is probably premature, as it also does not enable a healthy dialogue between stakeholders and patients.

\section{Legal considerations}

Laws differ from one country to another, and their interpretation by clinicians may depend on a variety of different factors.

In France, the National Order of Physicians (Conseil National de l'Ordre des Médecins) states that the information given to patients must be "loyal, clear and appropriate"; this requirement has been confirmed by the Court of Cassation. While this leaves some room for interpretation, it seems to exclude the prescription of biosimilars without informing the patient. New legislation was introduced in 2017 (Article 96 of the 2017 French Social Security Financing law) that permits conditional biosimilar substitution. Substitution is only permitted if the patient is molecule-naive (that is, undergoing treatment with the molecule for the first time), and that the prescribing physician has not explicitly prohibited substitution. Further, the biosimilar should belong to the same group as the prescribed product (similar biologic group). Upon such substitution, the pharmacist must inform the prescribing physician, as automatic substitution is not permitted. Further substitution to another biosimilar is not permitted, and treatment continuity with the same biosimilar must be ensured.
However, given the absence of a legal decree to implement this law, the practice of substitution yet to occur.

In the United Kingdom, the Medicines and Healthcare Regulatory Agency (MHRA), National Health Service (NHS) of England and Scotland recommend that a reference drug or biosimilar be prescribed by brand name; these agencies do not recommend interchanging at the pharmacy level ("non-medical" substitution). However, both NHS England and NHS Scotland advise that switching between a reference product and its biosimilar, or among biosimilars, can be managed at the discretion of the prescriber in collaboration with the patient, and with appropriate monitoring in place. Once again, this, theoretically, imposes patient information on potential biosimilars prescription.

In Germany, The Paul Ehrlich Institute encourages prescriber-led switching. The use of biosimilar is encouraged for both treatmentnaive patients and for those who previously received the originator molecule. Prescribers are expected to inform patients on copayment options when they choose between a biosimilar and its reference product. Germany publishes a list of biosimilars, known as "bioidenticals," that can be substituted at the pharmacy level, unless the prescriber specifically prohibits substitution. These "bioidenticals" refer biosimilars to a reference biologic that are manufactured by the same manufacturer under the same manufacturing process, but sold under different trade names. Hence, even with the same active 
ingredient, some biosimilars are considered interchangeable at the pharmacy level (for automatic substitution), while others are not.

In summary, at the EU-state level, all actors seem to be increasingly confident in biosimilars, but still officially express the remaining concerns of prescribers and patients.

\section{Patients perspective}

U.S. and E.U. patients have different perspectives on health care. Current social welfare policies in the U.S. are firmly rooted in America's highly individualistic political culture. U.S. citizens remain devoted to an ideology of the minimal state and reliance on the free market. One should also insist on the fact that patients have a very different perspective on their disease and efficacy endpoints from those of clinicians running clinical trials and regulators. For example, when we assess the efficacy of anti-TNFs in Rheumatoid Arthritis, we use validated disease scores such as ACR 20, though most patients have even never heard of ACR 20. RA patients are more concerned with day-to-day tasks, such as how they are going to get dressed for the day. In the same way, a pipe is not a pipe in Magrit's famous painting, a pair of sock represents a daily challenge for RA patients, not just a simple, pair of socks (Figure 2).

Most recent literature [9-12] on this topic demonstrates that patients are poorly informed on what biosimilars really represent. In reality, a large number of patients in a recent survey, presented in February 2019 at a DII conference by a representative of a French IBD patient's organization, shared negative comments about biosimilars: "As usual, I get the cheapest treatment, probably because I am not worth more costly options, while other patients get better treatments." "Don't ask me to be cost-conscious when I feel already hit by a massive injustice, my IBD disorder." Some patients even report having an emotional bonding with the branded product: "I have a meeting with "Remi" (Remicade") for my next infusion." All of these comments and preconceptions render the adoption of biosimilars even more challenging.

This is very much in line with what has been discussed by Hobbes $\mathrm{T}$ [13]: "humans are necessarily and exclusively self-interested. All

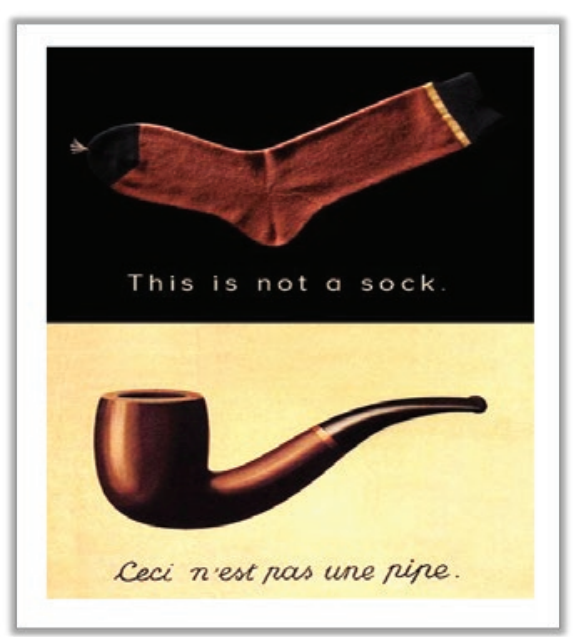

Figure 2: Free adaptation of the famous Magrit's Picture: this is not a pipe. men pursue only what they perceive to be in their own, individually considered, best interests."

In other words, patients do not see the personal benefits of biosimilars prescription, and indeed, at the individual level, these benefits are limited for well-insured patients.

On a positive note, we all (industry, regulators, clinicians) now tend to be "patient-centric" and actively consider, in compound, registration outcomes reported by the patients, the so-called Patients Reported Outcome (PRO). For instance, in the IBD drug assessment, $\mathrm{PRO}$ is even one of the co-primary endpoints that regulators request (together with endoscopic evaluation) in phase-3 clinical trials.

"One tweet a day keeps the doctor away": One should not underestimate the role of social media in terms of patient education. Three billion consumers have internet access, of which over two billion are social media users. Websites, such as www.patientslikeme. com, claim they have over 600,000 patients in their database, in which patients can find the relevant information they need and share their experiences on over 2,500 different diseases.

\section{Clinician's perspective}

If patients are not properly informed, it is, to a large extent, due to the fact that many clinicians are not fully aware of the nature, structure, function, immunogenicity, and efficacy/safety profile of biosimilars [12]. In a study reported by Cook JW, et al. [14], when asked to define a biosimilar, 74\% (57/77) of surveyed oncologists could not provide a satisfactory definition of biosimilars, and $40.3 \%$ (31/77) considered a biosimilar to be the same as a generic drug.

The perspective of prescribers has significantly evolved over the last couple of years. When the first anti-TNF biosimilars were developed in RA and ankylosing spondylitis, many gastroenterologists were very reluctant to extrapolate clinical data obtained in rheumatology and prescribe these biosimilars to patients with Inflammatory Bowel Disease (IBD) [15]. The European Crohn's and Colitis Organization (ECCO) actually stated that, "switching from an established biologic to a biosimilar to save costs is likely to be as inappropriate and ineffective as switching between current biologics that act on the same target, except when there is loss of response [16]."

This ECCO position was immediately challenged by European regulators. A survey of 307 ECCO members in 2014 conveyed that IBD specialists were reasonably informed on biologic agents, regarded cost sparing (89\%) as the main advantage, and listed immunogenicity $(67 \%)$ as their main concern. Sixty-four percent disagreed with automatic replacement of originator biologic agents with a biosimilar by a pharmacist, although $18 \%$ supported substitution for new prescriptions, and only $6 \%$ felt that biosimilars were interchangeable. However, with the accumulation of evidence of efficacy and safety of anti-TNF biosimilars in IBD patients, as reported by Avila-Ribeiro P, et al. [17] (23 observational studies, 12 of them assessing switching from infliximab originator to a biosimilar, and 17 assessing induction therapy with infliximab biosimilar), the position of most gastroenterologists has significantly evolved, and ECCO has recently revised their position, providing the following statements:

Biosimilarity is more sensitively characterized by performing suitable in vitro assays than clinical studies. Clinical studies of equivalence in the most sensitive indication can provide the basis for extrapolation. Therefore, data for the usage of biosimilars in IBD can be extrapolated from another indication. Ultimate demonstration of biosimilars safety requires large observational studies with long-term 
follow up in IBD patients.

Based on available literature, switching from the originator to a biosimilar in patients with IBD is acceptable. However, scientific and clinical evidence is still lacking regarding reverse switching, multiple switching, and cross-switching among biosimilars in IBD patients. What to communicate to patients is a matter of discussion among clinicians; in the same survey published by Cook JW, et al. [14], participants were split regarding the importance of shared decisionmaking with patients $50.7 \%$ (39/77) important or extremely important, $39.0 \%(30 / 77)$ somewhat or not at all important). One cannot exclude the psychological element that some clinicians are reluctant to see their prescription modified by the local pharmacist, the so-called "non-medical switching". Another challenge is that most prescribers only know the brand name of the compound, not its INN.

\section{Payer perspective}

The cost of treatments is, evidently, of great importance for payers; however, in discussion with many U.S. health organizations, the feedback was provided that a prerequisite to contracting is to demonstrate that biosimilar manufacturers and distributors had put in place a "reasonable" patient assistance program (PAP). Common statements included: "without a decent PAP, you will not be even invited to the negotiating table". Again, this further stresses the importance of working with patient advocacy organizations to design a program that truly provides them with the services and information they really need.

\section{Emerging Solutions}

\section{Approval is not the end-game}

With the new concept of biosimilars approval, based on the results in one single indication, regulators rightly require a risk-management plan and many clinicians recommend that a biosimilars efficacy/safety profile be investigated in post-approval disease registries in order to get real-world evidence data in a larger, more diverse population than that included in development trials.

One prerequisite is that traceability of administered biosimilars be guaranteed, so that a robust pharmacovigilance system and manufacturing risk management plan can deliver the data required. Evidently, naming heterogeneity/ lack of harmonization of biosimilars renders this issue more complicated.

\section{Many high-quality documents and training programs are already available}

Among others, the International Alliance of Patient's Organizations has developed a toolkit that provides patient organizations with upto-date, evidence-based information on the science, technology and regulatory information relevant to biologic originator and their biosimilar medicines, as well as tips on advocacy.

Since 2017, the EMA has published various informational materials as part of its ongoing collaboration to improving understanding of biosimilars across the European Union, including animated videos for patients, a biosimilar guide for health care professionals, as well as questions and answers on biosimilars for patients [18].

The FDA has recently announced that they have developed a free Continuing Education Course for healthcare professionals. This course was created for healthcare professionals to strengthen their knowledge and understanding of biosimilars and interchangeable products. The course is available to healthcare professionals on FDA's CDERLearn website, and can be completed on a tablet [16].

\section{Nurses are ideally placed in aiding patients to transitioning to biosimilars}

As mentioned in Armuzzi's paper [19], the recently updated Nurses-European Crohn's and Colitis Organization recommend that nurses facilitate the patient's choice of a biologic or biosimilar therapy; nurses are, indeed, pivotal in managing the concerns and challenges of transitioning to biosimilars. Recent evidence demonstrates that through nurse-led patient education and the use of structured communication strategies, as well as investing in managed switching programs, patients become more confident and adherent [9] to their biosimilars, which leads to significant health-care expenditure reduction, without compromising the safety and effectiveness of treatment.

\section{The emerging role of medical affairs/MSLS}

Medical Affairs scientists and Medical Science liaisons provide the bulk of information that healthcare professionals need in their practice; traditional sales representatives now have extremely limited access to prescribers, and commercial practices have come under increased scrutiny. Sales representatives cannot discuss any topic that is not strictly in line with the package insert/product labeling. Hence, the pharma industry has hired a large number of medical affairs liaisons/scientists. One of the challenges we face concerns the way in which necessary training to these MSLs is provided and validated. Many institutions are attempting to bridge this gap by developing a training course, such as the one developed by IFAPP (the International Federation of Associations of Pharmaceutical Physicians) and the IFAPP Academy [20] that has developed in collaboration with King's College in London.

\section{Incentivize clinicians to the drug budget}

There are multiple examples nowadays, in the U.S., of healthcare organizations and large hospitals that not only not inform clinicians regarding the challenge of burgeoning drug budgets, but also, in some instances, providing incentives to clinicians to ensure the drug budget is kept under reasonable control.

\section{Incentivize patients, (in the U.S., give rebates to patients!)}

Rebates and discounts given to Pharmacy Benefit Managers (PBMs) in the U.S. have played an important role in stymying biosimilar competition. Indeed, in the U.S., there is an industry-wide system of after-market discounts, known as "rebates" that pharmacy benefit managers (PBMs) receive from drug makers. This practice has been under increased scrutiny over the last couple of months. Quite recently, HHS proposed a rule to block these rebates and discounts. According to allegations made by Pfizer against Johnson and Johnson in an on-going antitrust lawsuit, Remicade-maker used the so-called "rebate trap" to block competition from infliximab biosimilars in the U.S. Unfortunately, the response to the proposed rule on rebates was mixed. Some organizations, such as the Community Oncology Alliance, viewed the plan to be, "extremely good news for patients", whereas the Academy of Managed Care Pharmacy labeled the plan's aim as "unrealistic." If finalized, the rule would change a system that has been in place for decades and that has been criticized for obfuscating the real price of prescription medicines. Fortunately, several highlevel pharma executives (Pfizer, AstraZeneca) now support passing all rebates to patients, highlighting that "today's rebates are swallowed up by the supply chain".

In Europe, as often used for generics, one should consider giving patients the option to be reimbursed based on biosimilars price, or 
being given the Reference compound, and paying the difference out of pocket.

\section{Do not let misleading statements about biosimilars go unchallenged}

The efforts of certain reference product sponsors to disseminate false and misleading information that cast doubt about the safety and efficacy of biosimilars in the minds of patients and prescribers is not acceptable and should be addressed; one example is the recent citizen petition to the FDA filed by Pfizer, in which the biosimilar developer asks the agency to issue guidance clarifying how drug sponsors communicate information about biosimilars. "Just as there is a need for policies that support innovation, there is also a need for policies that ensure that patients and physicians have truthful and non-misleading information that encourages appropriate uptake of biosimilars so that biosimilars can reach their full potential for patients," read the petition [21].

\section{Patients should be considered as partners, not "subjects"}

Over the last few years, the concept of "patient-centricity" has emerged; too long have patients been considered in clinical research as "subjects", and not as partners. Involvement of patients is now a regulatory requirement, and, in our experience, can contribute to a tremendous amount of value. At a recent CTTI Patient Groups and Clinical Trials Expert Meeting, Janet Woodcock (FDA) stated that it is critical for the clinical research community to recognize the shift from "patients as consumers", to "patients as partners" [22].

One step in this direction has manifested itself through the organization of the Patients Advisory Boards. In our experience, these boards enable to evaluate the kind of study outcome that really matters to patients, assess the feasibility of the study protocol, and ensure that the consent form is intelligible.

Our experience has highlighted the value of early interaction with patient organizations; this is a useful method to ensure that "informed consent" is truly informed, and that the results to be generated in a future clinical trial provide the true benefits patients rightly expect. Patients Advisory Boards can also help ensure that the intended clinical trial is "feasible" and not overly cumbersome, from the patient's perspective.

Not only should the patient be informed, but they should also be empowered, with knowledge being at the very core of what constitutes successful and effective patient empowerment. Patient empowerment means that patients play an active role in their health care management, and have a good understanding of engagement opportunities, and this should apply regardless of disease and country.

A relevant Patient Assistance Program, adapted to the national context, should always be actively considered; indeed, clinicians do not always have the time to address each and every question that patients may wish to pose, including whether and how the biologics are reimbursed.

\section{A new "Social contract"}

For XVIII century philosophers, morality was the result of an imaginary contract between rational agents who are agreeing upon rules to govern their subsequent behavior. It attempts to derive the content of morality from the notion of an agreement between all those in the moral domain. Contractarianism, a branch of utilitarianism, has its roots in Hobbes [23], whose account is based on mutual selfinterest. Morality exists in these forms of mutually advantageous, cooperative behavior for self-interested agents to engage in.
Immanuel Kant [24] can also be seen as a pioneer of Contract Theory. According to Kant, the sovereign must recognize the "original contract" as an idea of reason that forces the sovereign to, "give his laws in such a way that they could have arisen from the united will of a whole people and to regard each subject, insofar as he wants to be a citizen, as if he has joined in voting for such a will."

Locke's arguments for the social contract and for the right of citizens to revolt against their king were enormously influential on the democratic revolutions that followed, especially on Thomas Jefferson, and the founders of the United States.

The Social Contract seeks to address the question of how society can be free and live in cooperation. In other words, how can we live together without succumbing to the force and coercion of others? We can do so, Rousseau maintains, by submitting our individual, particular wills to the collective or general will, created through agreement with other free and equal persons.

In other words, the "Social Contract" as described by Jean-Jacques $\mathrm{R}$ [25], is an original contract between people, by which they accept a limitation to their freedom in exchange for laws guaranteeing solidarity and the perpetuation of the social body: "I seek to pursue my own interest in a way that I can justify to others who have their own interest to pursue."

Physicians must remember that their social contract with society extends beyond that of the individual patient and the medical profession, as it also reaches public and governmental domains. As public servants, physicians should heed Rousseau's warning:

"Every individual, as a man, may have a private will contrary to, or different from, the general will that he has as a citizen. His private interest may speak with a very different voice from that of the public interest; his absolute and naturally independent interest may make him regard what he owes to the common cause as a gratuitous contribution, the loss of which would be less painful for others than the payment is onerous for him (Figure 3)."

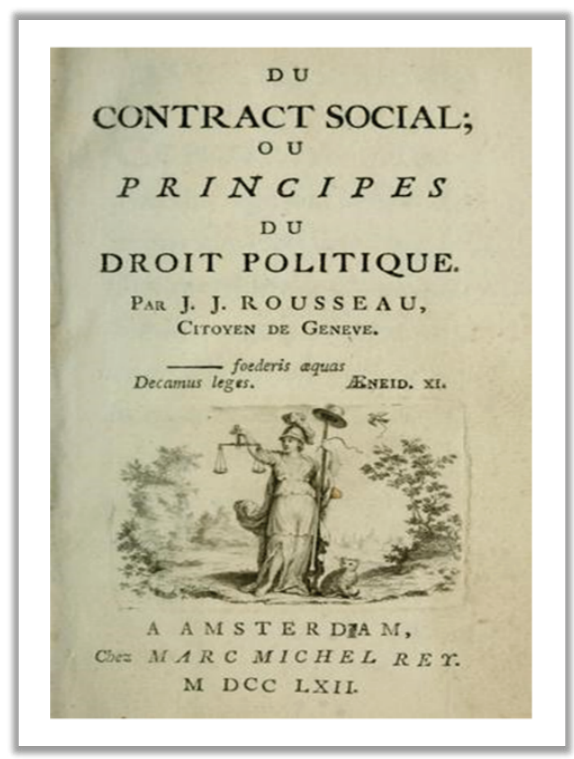

Figure 3: Cover page of J.J. Rousseau's Social Contract (Amsterdam, 1762). 
The relationship between the Social Contract and medicine has already been discussed by Cruess RL, et al. [26] in "Expectations and Obligations: Professionalism and Medicine's Social Contract with Society." In this article, Richard L and Sylvia R Cruess consider medicines' implicit duties to society. The authors note that, although well accepted as an appropriate model, the "social contract" in healthcare is a, "mixture of implicit and explicit, written and unwritten," obligations. To clarify, the authors subdivide "medicine" into individual physicians and the institutions of medicine. "Society" is divided into individual patients, the public, and the government. In the triangulation among medicine, government, and society, "the balance of power and influence shifts from time to time, and, as society evolves, so must the social contract."

In the journal, "Access to essential medicines", Ashcroft RE [23] discusses the "Hobbesian Social Contract"; the author notes the paradigm created by the HIV pandemic and various state (moral, political, etc.) obligations to grant compulsory licenses to anti-HIV drugs. The HIV/AIDS pandemic, and the high cost of treatments for HIV infection, have indeed drawn considerable attention over the past few years to the question of how far sovereign states are permitted to use compulsory licensing powers to compel pharmaceutical companies to either sell essential medicines at greatly reduced prices, or compel them to permit generic drug manufacturers to enter the market in order to drive down prices. In the United Kingdom, for instance, the law of intellectual property permits the state to compulsorily license inventions for 'Crown Use', and this has included compulsory licensing of drugs for prescription under the NHS. The Doha meeting of the World Trade Organization (WTO) established that, under the terms of the Trade Related Intellectual Property Rights division of the WTO agreement, states do, indeed, have the compulsorily power to license innovations for health-related reasons, but that this must be exercised after due consultation, and with fair reimbursement to rights-holders.

It is suggested here that the adoption of biosimilars represents a typical example of an evolving "social contract", in which informed patients agree to receive a biosimilar prescription enabling access to expensive biologics to more patients. This, in our opinion, is the most effective way for patients to accept a biosimilar that does not, in fact, provide them with any short-term personal benefits. Patients should also be made aware that a short-term, egoistic request to receive, in their words: "the best possible treatment", might have long-term consequences on the viability of the modern health care systems, such as the one we currently enjoy in Western Europe. These systems are currently in jeopardy, and politicians should have the courage to tell their electors that these systems require significant funding, and that cost-effective health care solutions that do not jeopardize patient wellbeing should be implemented.

\section{Conclusion}

Biosimilars represent a unique opportunity to provide access to biotherapeutics to a larger patient population. Despite recent progress in this area, particularly in analytical and regulatory sciences, significant hurdles hinder many countries from adopting biosimilars on a large scale, such as intellectual property and the misperception on what biosimilars really are at all levels (patients, prescribers, politicians, etc.). The notion that reference compounds actually change over time seems to be one of the best kept secrets. There is, in 2019, sufficient evidence that recently marketed biosimilars have provided all of the necessary evidence of comparable efficacy and safety/ immunogenicity; however, the introduction of biosimilars cannot be imposed. Training, support from independent medical societies, education of all stakeholders, consensus building, and the revival of the concept of "social contract" can, and must, be achieved through partnering and education. This will enable a faster adoption of biosimilars, and give access to new biotherapeutics and life-saving, innovative medications to the patients who need them.

\section{References}

1. Frapaise FX (2018) The End of Phase 3 Clinical Trials in Biosimilars Development? BioDrugs 32: 319-324.

2. Schneider CK (2013) Biosimilars in rheumatology: the wind of change. Ann Rheum Dis 72: 315-318.

3. Mehr SR, Zimmerman MP (2016) Is a Biologic Produced 15 Years Ago a Biosimilar of Itself Today? Am Health Drug Benefits 9: 515-518.

4. Lamanna WC, Mayer RE, Rupprechter A, Fuchs M, Higel F, et al. (2017) The structure-function relationship of disulfide bonds in etanercept. Sci Rep 7: 3951.

5. Olteanu R, Constantin M, Zota A (2018) Biosimilars: A Review of Published Randomized Control Trials Comparing Biosimilars with their Reference Products. Adv Tech Biol Med 6: 252.

6. Cohen HP, Blauvelt A, Rifkin RM, Danese S, Gokhale SB, et al. (2018) Switching Reference Medicines to Biosimilars: A Systematic Literature Review of Clinical Outcomes. Drugs 78: 463-478.

7. Pouillon L, Socha M, Demore B, Thilly N, Abitbol V, et al. (2018) The nocebo effect: A clinical challenge in the era of biosimilars. Expert Rev Clin Immunol 14: 739-749.

8. Boone NW, Liu L, Romberg-Camps MJ, Duijsens L, Houwen C, et al. (2018) The nocebo effect challenges the non-medical infliximab switch in practice. Eur J Clin Pharmacol 74: 655-661.

9. Jacobs I, Singh E, Sewell KL, Al-Sabbagh A, Shane LG (2016) Patient attitudes and understanding about biosimilars: an international cross-sectional survey. Patient Prefer Adherence 10: 937-948.

10. Hoque T, Suddle A, Herdman L, Kitchen J (2018) Patient perceptions of switching to biosimilars. Rheumatology 57: 072.

11. van Overbeeke E, De Beleyr B, de Hoon J, Westhovens R, Huys I, et al. (2017) Perception of Originator Biologics and Biosimilars: A Survey Among Belgian Rheumatoid Arthritis Patients and Rheumatologists. BioDrugs 31: 447-459.

12. Teeple A, Ellis LA, Huff L, Reynolds C, Ginsburg S, et al. (2019) Physician attitudes about non-medical switching to biosimilars: results from an online physician survey in the United States. Curr Med Res Opin 35: 611-617.

13. Hobbes $T$ (1651) Leviathan.

14. Cook JW, McGrath MK, Dixon MD, Switchenko JM, Harvey RD, et al. (2019) Academic oncology clinicians' understanding of biosimilars and information needed before prescribing. Ther Adv Med Oncol 11: 1-12.

15. Frantzen L, Cohen JD, Tropé S, Beck M, Diebold R, et al. (2018) Patients' concerns about and perception of biosimilars in rheumatology: A french survey. Ann Rheum Dis 77: FRI0126.

16. USFDA (2018) Biosimilars Action Plan Balancing innovation and competition. Maryland, USA.

17. Avila-Ribeiro P, Fiorino G, Danese S (2017) The experience with biosimilars of infliximab in inflammatory bowel disease. Curr Pharm Des 23: 6759-6769.

18. European Medicines Agency, The European Commission (2017) Biosimilars in the EU: Information guide for healthcare professionals. UK. 
19. Armuzzi A, Avedano L, Greveson K, Kang T (2019) Nurses are critical in aiding patients transitioning to biosimilars in inflammatory bowel disease: education and communication strategies. J Crohns Colitis 13: $259-266$.

20. The IFAPP-Kings College Medical Affairs in Medicines Development Certification Program Details.

21. FDA news Drug Daily Bulletin (2018) Pfizer Calls for Guidance on Misleading Biosimilar-Related Communications. USA.

22. Valentine JE (2015) CTTI Releases Recommendations and Tools to Maximize Engagement between Research Sponsors and Patient Groups. FDA Law Blog.
23. Ashcroft RE (2005) Access to essential medicines: A Hobbesian social contract approach. Dev World Bioeth 5: 121-141.

24. Chun-yip L (2019) Kant's Social contract: A New Transcendental Principle in Political Philosophy 91-111.

25. Jean-Jacques R (1895) The Social Contract; or, Principles of Political Rights. George Allen and Unwin, The Ohio State University, USA.

26. Cruess RL, Cruess SR (2008) Expectation and obligations: professionalism and medicine's social contract with society. Perspect Biol Med 51: 579-598. 